\title{
A cadeia de logística reversa de resíduos de serviços de saúde dos hospitais públicos de Minas Gerais: análise a partir dos conceitos da nova Política Nacional de Resíduos Sólidos Urbanos
}

\section{The Reverse Logistics Chain of Health Services Waste from Public Hospitals in Minas Gerais: an Analysis through the Concepts of the New Brazilian National Solid Waste Act}

\author{
André Luiz PEREIRA* \\ Sandra Rosa PEREIRA**
}

\begin{abstract}
RESUMO
A problemática do meio ambiente tem sido motivo de preocupação das nações em virtude das consequências das atividades antrópicas na qualidade de vida da população e ambiental. A Organização das Nações Unidas - ONU, enquanto organismo internacional de congregação das nações, tem promovido a discussão e o envolvimento dos países para a adoção de medidas de responsabilização com o meio ambiente. O Brasil, do ponto de vista jurídico, tem avançado positivamente na implementação de mecanismos que propiciam políticas ambientais. Exemplos desta preocupação estão no caráter protecionista destacado na Constituição da República de 1988, os variados conselhos, sistemas ambientais e, mais recentemente, a edição da Lei 12.305/10, disciplinando aspectos importantes relacionados à gestão dos Resíduos Sólidos Urbanos. A lei atenta para a prevenção da geração de Resíduos Urbanos e a segurança ambiental e das pessoas. Assim, este estudo qualitativo descritivo-exploratório aborda a Logística Reversa de Resíduos de Serviços de Saúde para os hospitais públicos mineiros, o papel e as responsabilidades do poder público e da iniciativa privada. Como conclusão, os hospitais públicos mineiros precisam passar por grande readequação de modo a atender aos requisitos legais da Lei 12.305/10.
\end{abstract}

Palavras-chave: resíduos sólidos urbanos; Política Nacional de Resíduos Sólidos; Logística Reversa.

\footnotetext{
* Administrador (UESB), especialista em Acreditação de Serviços de Saúde (FCMMG), MBA em Administração Hospitalar (FACINTER) e Mestre em Administração - Logística Reversa (Universidade FUMEC). Professor da Universidade FUMEC. Email: andre@logisticareversa.net.br

*" Administradora e advogada (UESB), especialista em Administração Pública (UEFS) e Auditoria Fisco-Contábil (Fundação Visconde de Cairú). Auditora Fiscal da Secretaria da Fazenda do Estado da Bahia. Inspetora Fiscal da IFEP. Email: srosa@sefaz.ba.gov.br
} 


\begin{abstract}
The environment has been a nation's concern because of the consequences of human activities on life and environmental quality. The United Nations - UN, as an international congregation, has promoted various discussions and involvements of countries to adopt accountability measures towards the environment. Brazil, by the legal point of view, has moved positively into the implementation of mechanisms that promote environmental policies. Examples of this concern are highlighted in protectionist measures in the 1988 Constitution, the various councils and environmental systems, and more recently the Law nr. 12.305/10, setting important aspects in the management of Urban Solid Waste. This law attempts to prevent the waste production, and improve people and environmental safety. Thus, this qualitative study, with a descriptive-exploratory approach, refers to reverse logistics of health services waste from the public hospitals in Minas Gerais, the role and responsibilities of public and private management. In conclusion, the public hospitals of Minas Gerais state should change their management to achieve all the law 12,305/10 requirements.
\end{abstract}

Key-words: urban solid waste; Brazilian National Solid Waste act; Reverse Logistics.

\section{Introdução}

A fim de atender às variadas e complexas necessidades da sociedade por consumo, exige-se que haja a transformação dos recursos naturais em produtos beneficiados, os quais, ao completarem o ciclo de sua vida útil, acabam por ser descartados. Ao longo do tempo, com o crescimento populacional e a constante capacidade humana de transformar o meio ambiente, essa dinâmica passou a se constituir num problema. À medida que a relação consumo x produtividade passou a demonstrar que deveria haver limites ao processo de exploração da natureza, constatou-se que esta última não tem conseguido reciclar os resíduos descartados numa velocidade compatível com a produção humana. $\mathrm{O}$ resultado disso são os lixões, a poluição e a degradação ambiental decorrente do acúmulo e da produção de resíduos pelos humanos.

Assim, para que haja a compreensão da cadeia de produção de resíduos e o seu manejo de forma sustentável e segura, numa perspectiva de ganho econômico e promoção da saúde coletiva, é preciso a adoção do gerenciamento logístico, de modo a contemplar as variáveis pertinentes. Esta pesquisa teve como objetivo geral analisar a nova Política Nacional de Resíduos Sólidos - PNRSU, aplicando seus conceitos, e a Logística Reversa aos hospitais públicos de Minas Gerais (participantes do programa estadual Pro-hosp). Como objetivos específicos, procurou-se delimitar as responsabilidades da sociedade/ONGs, do governo e das empresas na PNRSU e aplicar o modelo proposto à cadeia Logística Reversa de Resíduos de Serviços de Saúde (RSS) dos hospitais Pro-hosp de Minas Gerais.
Após tramitar duas décadas no Congresso, finalmente foi promulgada a Lei $\mathrm{n}^{\mathrm{o}}$ 12.305, em 2 de agosto de 2010, que estabeleceu a obrigatoriedade da Logística Reversa no país, a qual deve envolver como atores governo, empresas e sociedade civil/ONGs, representando um grande avanço, uma vez que institucionaliza a responsabilidade e a corresponsabilidade de cada participante da cadeia de suprimentos e resíduos. Por ser algo novo, há a necessidade de instrumentalizar a PNRSU por meio da elaboração de modelos sistemáticos de análise.

\section{Meio ambiente e sustentabilidade}

A Organização das Nações Unidas (ONU) convocou em 1968, por intermédio de sua Assembleia Geral, a realização da primeira Conferência das Nações Unidas sobre o Meio Ambiente Humano. Obstavam as consequências da ação antrópica no meio ambiente, que já se desnudavam à época. Concretizada em 1972 na cidade de Estocolmo, a conferência buscou a convergência das nações para a discussão do meio ambiente humano e suas soluções. Da Declaração de Estocolmo sobre o Meio Ambiente Humano, o princípio $\mathrm{n}^{\circ} 19$ destaca a importância da educação ambiental, dirigida tanto às gerações jovens quanto aos adultos, com a observância da população menos privilegiada, fundamentada nas bases de uma opinião pública bem informada e de uma conduta dos indivíduos, das empresas e das coletividades inspirada no sentido de sua responsabilidade sobre a proteção e o melhoramento do meio ambiente em toda sua dimensão humana. 
O princípio destaca, entre outras, a necessidade de se envolver os indivíduos nas questões ambientais para a formação de condutas humanas responsáveis como fator primordial de sucesso na implementação de políticas de proteção ao meio ambiente. Neste mesmo sentido, reafirma a Declaração do Rio em seu artigo 10, documento gerado pela segunda Conferência realizada no Rio de Janeiro, em 1992, que a melhor maneira de tratar questões ambientais é assegurar a participação, no nível apropriado, de todos os cidadãos interessados. O nível nacional deve priorizar o adequado acesso às informações relativas ao meio ambiente de que disponham as autoridades públicas, inclusive informações sobre materiais e atividades perigosas em suas comunidades. Deve-se priorizar também a conscientização e a participação pública como a participação social em processos de tomada de decisão. Isso é uma questão de defesa da dignidade humana e da qualidade de vida em coletividade, bem como o respeito ao meio ambiente.

Para que a dignidade da pessoa humana possa se efetivar concretamente no seio da sociedade brasileira nas questões relacionadas à qualidade de vida da coletividade, o Estado tem que agir de modo mais contundente no envolvimento dos cidadãos neste processo. Visa promover a proteção ao meio ambiente e o combate à poluição em todas as suas formas (art. 23, VI, CR/88), uma vez que a responsabilidade pela qualidade de vida/meio ambiente é de competência comum à União, Estados, Distrito Federal e Municípios (art. 23, caput, CR/88) e:

Art. 225. Todos têm direito ao meio ambiente ecologicamente equilibrado, bem de uso comum do povo e essencial à sadia qualidade de vida, impondo-se ao Poder Público e à coletividade o dever de defendê-lo e preservá-lo para as presentes e futuras gerações.

$\S 1^{\circ}$ - Para assegurar a efetividade desse direito, incumbe ao Poder Público:

[...]

VI - promover a educação ambiental em todos os níveis de ensino e a conscientização pública para a preservação do meio ambiente; [...] (BRASIL, 1988).
Há que se registrar o aspecto inovador advindo do caráter constitucional atribuído à matéria ambiental, não contemplada nas constituições brasileiras anteriores à Constituição de 1988, ainda que mereça referência a Política Nacional do Meio Ambiente ${ }^{1}$ instituidora do SISNAMA, Lei $n^{\circ} 6.938 / 81$, que define poluição como degradação da qualidade ambiental resultante de atividades que:

a) prejudiquem a saúde, a segurança e o bem-estar da população;

b) criem condições adversas às atividades sociais e econômicas;

c) afetem desfavoravelmente a biota;

d) afetem as condições estéticas ou sanitárias do meio ambiente;

e) lancem matérias ou energia em desacordo com os padrões ambientais estabelecidos.

Através de uma visão econômica, é preciso também legitimar a necessidade dos indivíduos serem responsáveis pela preservação do meio ambiente, determinação recorrente na Constituição:

Art. 170. A ordem econômica, fundada na valorização do trabalho humano e na livre iniciativa, tem por fim assegurar a todos existência digna, conforme os ditames da justiça social, observados os seguintes princípios: $[\ldots]$

VI - defesa do meio ambiente, inclusive mediante tratamento diferenciado conforme o impacto ambiental dos produtos e serviços e de seus processos de elaboração e prestação. (BRASIL, 1988).

$\mathrm{Na}$ esteira desta evolução no campo legal relacionado à proteção ambiental, destaca-se a edição da Lei $n^{0}$ 12.305/2010, intitulada Lei de Resíduos Sólidos, como mecanismo de fomento à sustentabilidade ambiental no âmbito dos resíduos/rejeitos gerados pela produção e consumo na sociedade, atribuindo-se aos seus produtores, de forma

\footnotetext{
${ }^{1}$ Lei n ${ }^{\circ} 6.938 / 81$ - Art. $2^{\circ}$. A Política Nacional do Meio Ambiente tem por objetivo a preservação, melhoria e recuperação da qualidade ambiental propícia à vida, visando assegurar, no País, condições ao desenvolvimento socioeconômico, aos interesses da segurança nacional e à proteção da dignidade da vida humana, atendidos os seguintes princípios:

I - ação governamental na manutenção do equilíbrio ecológico, considerando o meio ambiente como um patrimônio público a ser necessariamente assegurado e protegido, tendo em vista o uso coletivo; [...]
} 
solidária, a responsabilidade pelo descarte adequado dos mesmos, norteando a política de saneamento a ser adotada pelo poder público.

Não se pode ignorar que o conceito de sustentabilidade também se relaciona à forma como se pode ter garantidos os insumos dos quais se prescinde. Romeiro (1998, p. 248) afirma que "o desenvolvimento para ser sustentável, deve ser não apenas economicamente eficiente, mas também ecologicamente prudente e socialmente desejável”. Esta visão encaixa na perspectiva de ação abordada.

Conforme Goto e Souza (2008), a questão ambiental nas organizações aumenta sua visibilidade na década de 1970, momento em que os consumidores apresentam maior consciência ambiental e isso começa a se refletir no comportamento das indústrias de bens de consumo ou serviços. A relevância do tema foi se acentuando no início da década de 1980, mas somente a partir da década de 1990 cresceu a preocupação sobre os impactos ambientais causados por materiais e produtos que, no seu pós-uso, são depositados de forma inadequada na natureza. O escopo e a escala das atividades de reciclagem e reaproveitamento de produtos e embalagens têm aumentado consideravelmente nos últimos anos. $\mathrm{O}$ "desenvolvimento sustentável significa atender às necessidades do presente, sem comprometer a capacidade das gerações futuras de atender as suas próprias necessidades" (CMMAD, 1988, p. 28).

\section{Relacionando Logística Reversa e resíduos}

O Council of Supply Chain Management Professionals (2010) define a Logística Reversa - LR como "um segmento especializado da Logística que enfoca o movimento e o gerenciamento de produtos e bens depois da venda e depois da entrega ao cliente. Inclui o retorno de produtos para reparo e/ou crédito" (CSCMP, 2010, p. 161). Já Lambert, Stock e Vantine (1999) ressaltam que a Logística Reversa considera tópicos como redução/conservação da fonte, reciclagem, substituição e descarte, questões importantes que fazem a interface com as atividades logísticas de compras e suprimentos, tráfego e transporte, armazenagem e estocagem e embalagem (LAMBERT; STOCK; VANTINE, 1999).

Neste contexto, a literatura em Logística Reversa tem versado principalmente sobre manufaturados, uma vez que questões relacionadas a devoluções, produtos defeituosos, defasados e descarte de embalagens têm sido foco de co- branças por responsabilidade ambiental pelos consumidores, fazendo com que a Logística Reversa se consubstancie e ganhe maior vigor, exigindo maior eficiência e eficácia da cadeia Logística Reversa.

Segundo Rogers e Tibben-Lembke (1999), existem alguns fatores para a elaboração de uma cadeia Logística Reversa eficiente, tais como Controles de Entrada (Gatekeeping); Mapeamento e Formalização do Processo; Tempo de Ciclo dos Produtos; Sistemas de Informação; Infraestrutura Logística; e Relações entre Clientes e Fornecedores. Os dois grandes ramos da Logística Reversa, de acordo com estes autores, são a LR de pós-consumo e a LR de pós-venda. Nesta revisão teórica, o foco é esta última, atingindo a gestão de resíduos descartáveis.

Há que se salientar o papel do marketing nesse processo, já que a Logística representa um papel-chave na satisfação dos clientes das empresas, bem como em sua lucratividade como um todo. Bowersox e Closs (2001) referem-se ao "apoio ao ciclo de vida", que seria um dos alvos da logística contemporânea, pois esta última ultrapassaria o fluxo direto dos materiais. Geraria uma necessidade de considerar os fluxos reversos de produtos.

Para Dornier et al. (2000, p. 40): "No início os investimentos em logística focaram-se principalmente no fluxo das empresas para o mercado (fluxo direto)". Richardson (2001) afirmava que na época as indústrias só passaram a pensar em Logística Reversa quando os produtos rejeitados ou devolvidos apareciam à sua frente. Assim, quando a logística percebeu que poderia incluir dados sobre o retorno de produtos manufaturados como um indicador de qualidade para a análise dos índices de devoluções, esta informação passou a ser um agregador de valor e a Logística Reversa ganhou força.

A análise do gerenciamento reverso de resíduos de serviços de saúde traz ao saber científico a visão sistêmica e integrada da problemática dos materiais descartados. É possível compreender como o distribuidor, o gerador de resíduos e o descarte final se inserem em uma mesma cadeia pela qual todos são responsáveis. Conhecer essa rede demanda um método científico, sistematizado e replicável, ampliando as aplicações, agregando conhecimentos à área de Logística Reversa.

O papel das ONGS, cooperativas e associações de reciclagem e triagem de resíduos é fundamental na cadeia Logística Reversa. Os catadores e agentes de reciclagem coletam o material descartado, encaminhando às organizações por meio dos entes supracitados para que sejam reinseridos nos processos produtivos. 


\subsection{A problemática dos resíduos sólidos urbanos no Brasil}

Segundo Cunha e Caixeta Filho (2002), parcela significativa dos municípios brasileiros não coletam e/ou promovem uma destinação adequada aos resíduos sólidos produzidos em seu território, os quais, via de regra, acabam por ser depositados a céu aberto, sem receber tratamento inibidor ou redutor dos efeitos poluidores. Este é um paradigma cuja transformação requer a intervenção de todos os atores pertencentes à sociedade, governo e empresas, sendo importante destacar a atuação de organizações não governamentais - ONGs - no processo de coleta seletiva e Logística Reversa.

Observa-se que a participação governamental é fundamental no processo de gerenciamento reverso da cadeia de resíduos, considerando que é um preceito legal do Estado fiscalizar a correta destinação dos resíduos em geral. O papel da Logística Reversa, aqui, significa relevante contribuição para a adoção de políticas públicas de gerenciamento de resíduos sólidos urbanos, de forma a promover a atenuação do seu impacto ambiental, aumentando a segurança do transporte e do manuseio de resíduos, a redução de seu volume e dos custos de seu manuseio, bem como outros impactos.

A competência legal da disposição de resíduos é também da empresa geradora, devendo haver no município ou em área próxima um aterro sanitário ambientalmente adequado e regulamentado. Cabe aos instrumentos de participação social previstos na Política Nacional de Resíduos Sólidos Urbanos acompanhar a gestão de resíduos, tornando o processo sistêmico. Por sua vez, as organizações não governamentais que trabalham com reciclagem e triagem de resíduos também possuem extremo interesse na nova política e na Logística Reversa de Resíduos, pois é de onde provêm seus recursos.

\subsection{Manejo de resíduos de serviços de saúde}

Os Resíduos Sólidos Urbanos - RSU - são compostos de vários tipos de materiais descartados, como os domésticos, industriais, da construção civil, de serviços de saúde etc. Os Resíduos de Serviços de Saúde - RSS - são classificados, conforme a RDC 306/2004, em cinco grupos: A (risco biológico), B (químico), C (radioativos), D (comuns) e E (perfurocortantes)
A Logística Reversa, ao estabelecer a necessidade do gerenciamento reverso estatal, possibilita ao Estado gerir os Resíduos de Serviços de Saúde de forma eficiente e segura para a saúde da população e para o meio ambiente. Esta é uma atuação importante no âmbito do Sistema Único de Saúde - SUS - que centraliza as ações em saúde coletiva no país, conforme preconizado pela Constituição Federal, sendo tema da Lei $\mathrm{n}^{\circ} 12.305 / 2010$, que regulamenta a Política Nacional de Resíduos Sólidos e institucionaliza a Logística Reversa em todo o país (BRASIL, 2010).

Beneficiando-se dessa questão, o SUS pode, assim, gerenciar os Resíduos de Serviços de Saúde de maneira a prevenir os riscos (biológicos, químicos, perfurocortantes, radioativos), evitando que se ocasionem dano à saúde da população. O simples fato de se efetuar depósito de resíduos no solo ou aterrá-los não os reintegra a uma cadeia produtiva, sendo necessária uma política efetiva de gerenciamento de uma cadeia de valor que seja sustentável, gerando ganho econômico e saúde para a comunidade. Ciplet (2006) afirma que os recursos naturais são desperdiçados quando são queimados ou simplesmente direcionados aos aterros. Sendo limitados, perder a oportunidade de reciclar e dar nova destinação é improcedente. "O processo de reciclagem traz benefícios para a comunidade, pois gera empregos e renda, além de contribuir para a redução da poluição ambiental, pois menos resíduos são depositados em aterros, e ainda implica o menor gasto de recursos naturais" (GARCIA; ZANETTI-RAMOS, 2004, p. 749).

Além disso, quando há formas de reentrada dos resíduos em cadeias produtivas, estes adquirem valor econômico, gerando ganhos em transporte, armazenagem, produção e matérias-primas No Brasil e em Minas Gerais, o que se observa é um comportamento "de tudo ou nada": ou todos os resíduos são segregados como perigosos, ou nada é separado e os Resíduos de Serviços de Saúde acabam sendo dispostos como resíduos comuns ou domiciliares (GARCIA; ZANETTI-RAMOS, 2004; LUIZ-PEREIRA; COELHO, 2009).

Os hospitais, por realizarem vários procedimentos que geram Resíduos de Serviços de Saúde e pelo grande volume produzido, merecem especial atenção (GARCIA; ZANETTI-RAMOS, 2004; SILVA; HOPPE, 2005), estando os hospitais públicos e filantrópicos mineiros pertencentes ao SUS - considerados referência nas micro e macrorregiões - participando do Pro-hosp. Por isso, esta pesquisa aborda o universo destes hospitais, geradores de Resíduos de Serviços de Saúde, conforme previsto na Resolução 
$\mathrm{RDC} \mathrm{n}^{\circ} 306 / 2004$ e sujeitos também à Lei n ${ }^{\circ} 12.305$, aplicando os conceitos da nova Política Nacional de Resíduos Sólidos Urbanos à cadeia Logística Reversa de Resíduos de Serviços de Saúde. Em virtude do exposto, compreende-se a responsabilidade do Sistema Único de Saúde - SUS - no processo de gerenciamento reverso da cadeia de Resíduos de Serviços de Saúde. Segundo Machado et al. (2007, p. 337), "a partir da implementação do SUS, não só foi desencadeado um processo de ampliação na quantidade de serviços de saúde, como também na qualidade destes, já que um de seus princípios é o da integralidade [...]”.

Em Minas Gerais, a atenção hospitalar à saúde no SUS conta com um programa que estabelece uma parceria entre o Estado e os hospitais públicos e filantrópicos prestadores de serviços para o SUS/MG, envolvendo a participação dos gestores municipais, Conselhos de Saúde Municipal e o Conselho Estadual de Saúde (MINAS GERAIS, 2006b). É denominado Programa de Fortalecimento e Melhoria da Qualidade dos Hospitais do SUS/MG - Pro-hosp. São 127 hospitais participantes do programa.

\section{Métodos}

A pesquisa que deu base a esse artigo foi basicamente descritiva na acepção de que focalizou as características de determinadas populações ou fenômenos (MARCONI; LAKATOS, 1995), embora tenha procurado iniciar uma análise dos seus principais resultados. Utilizou-se técnicas padronizadas de coleta de dados, tais como o questionário e a pesquisa bibliográfica e documental.

O questionário foi elaborado de forma a avaliar a cadeia Logística Reversa de Resíduos de Serviços de Saúde conforme a Política Nacional de Resíduos Sólidos. Foram aplicados 46 questionários em 127 hospitais públicos mineiros participantes do Pro-hosp, que é um programa de saúde ligado à Secretaria de Estado de Saúde de Minas Gerais. Os resultados alcançados foram comparados com as bases de dados oficiais, além de verificações in loco. Os resultados são apresentados descritivamente, partindo do modelo teórico até a percepção da realidade, sistematizando a prática segundo a modelagem proposta. Os resultados da análise da nova Política Nacional de Resíduos Urbanos são apresentados primeiro, para introduzir a Figura 2, que descreve os dados coletados via questionário e observação sistemática, colocando a sistemática da Figura 1 na prática.
A pesquisa bibliográfica versou sobre as áreas do conhecimento requeridas para a compreensão da Política Nacional de Resíduos Sólidos. A pesquisa documental tratou do texto da lei 12.305 , de 2 de agosto de 2010 e do Decreto $\mathrm{n}^{\circ} 7.404$, de 23 de dezembro de 2010. Este artigo apresenta parte dos dados coletados.

\section{Resultados}

$\mathrm{O}$ advento da Lei $\mathrm{n}^{\circ}$ 12.305/2010 tornou-se um marco histórico na gestão de resíduos no Brasil ao instituir a Política Nacional de Resíduos Sólidos e superar aspectos de caráter subjetivo na discussão do tema, normatizando-o. Quando se pensava na questão dos resíduos no Brasil, a responsabilidade dos atores envolvidos era um tema complexo e de difícil definição dos papéis legais. Agora o poder público, o setor empresarial e a coletividade são oficialmente responsáveis por toda a cadeia de resíduos e suas consequências, numa relação que não se extingue com a terceirização ou a atribuição de etapas a terceiros, exceto no caso do gerador doméstico, o que é um avanço. Estes últimos passam a ter que devolver aos fabricantes ou importadores os produtos descartados passíveis de Logística Reversa descritos na lei, bem como determinadas embalagens.

\subsection{Sistematização dos conceitos da nova Política Nacional de Resíduos Sólidos Urbanos}

A Figura 1 apresenta o mapa conceitual que representa as responsabilidades e compartilhamento de ações segundo três perspectivas: sociedade/ONGs, empresas e governo.

A tripartição das responsabilidades entre sociedade, governo e empresas é o que dá o caráter sistêmico da Política Nacional de Resíduos Sólidos. A Figura 1 apresenta os principais relacionamentos segundo essa nova política. No centro da figura destacam-se a educação ambiental continuada, a gestão integrada de resíduos, a prática do 3R (reduzir, reutilizar e reciclar), a Logística Reversa em si e na sua estruturação como sistema, em simbiose com a coleta seletiva.

A política avança muito na questão da gestão colegiada, incluindo a participação social (parágrafo único do Art. 14), pois replica o modelo usado nos conselhos e planos consagrados na saúde e educação, com a criação de conselhos locais, regionais e nacionais relacionados a resíduos. 


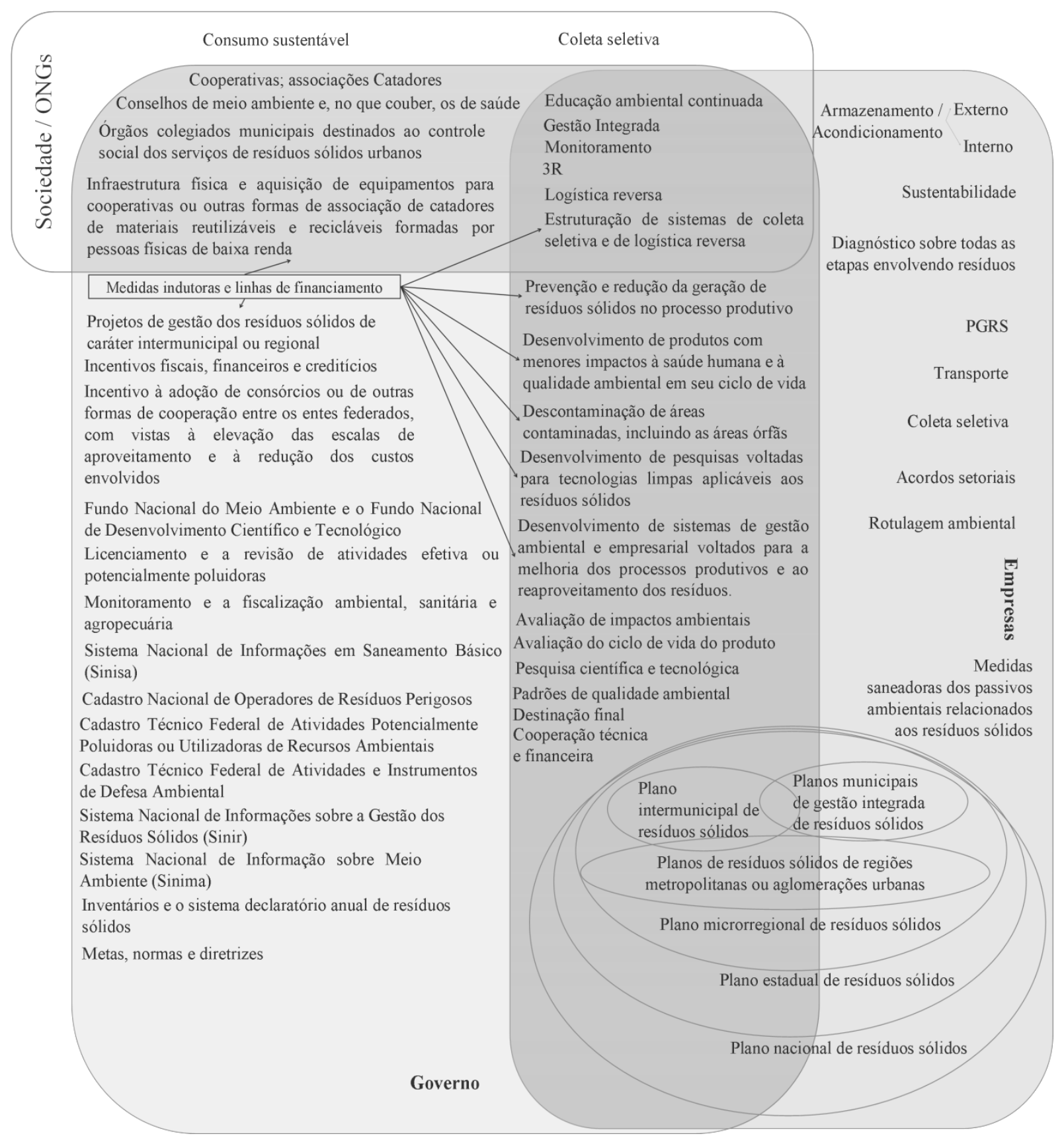

FIGURA 1 - MAPA CONCEITUAL DAS PRINCIPAIS RELACIONAMENTOS SEGUNDO A POLÍTICA NACIONAL DE RESÍDUOS SÓLIDOS.

FONTE: Elaboração própria. 
Os resíduos passam a ser analisados em perspectivas micro - em cada nó do ciclo de resíduos e na municipalidade/microrregião - e macro - segundo a territorialidade estadual e federal. O gerador se verá obrigado a pensar na sua gestão interna e externa, bem como na cadeia de resíduos indireta como um todo. Até então, a gestão do descarte era cobrada em nível municipal pela maior parte dos Estados e em nível microrregional, em poucos entes da federação. Uma das vantagens da perspectiva microrregional é aumentar a escala de uso das destinações finais corretas e diminuir os custos de investimento, além de compartilhar despesas de manutenção para cada um dos municípios relacionados, acelerando a implementação de soluções, conforme descrito na Figura 1. Pequenos municípios, com poucos recursos e baixo volume de geração de resíduos, podem se unir em prol da construção de centros de triagem/ compostagem/ aterro sanitário que atendam a todos.

Setores como construção civil, atividades agroindustriais e tantas outras passam a ter também um foco central na importância do material descartado. Vale dizer que os Resíduos Sólidos Urbanos passam a ser considerados um recurso de valor agregável e não apenas um problema a ser contornado, advindo a necessidade de criação de fontes de negócio, emprego e renda.

Para agregar valor àquilo que não se quer mais, a primeira etapa é o planejamento, previsto na lei como os planos de gerenciamento, os diagnósticos situacionais, a proposição de metas, programas, normatizações, planos, planejamento estratégico e o estabelecimento de cenários. O Plano de Gerenciamento de Resíduos, comumente associado aos geradores de Resíduos de Serviços de Saúde e construção civil, amplia seu escopo clássico, abarcando claramente também os geradores de resíduos perigosos, resíduos não domiciliares, atividades agrossilvopastoris e as empresas de transporte que lidam com estes resíduos, que antes da lei tinham diretrizes governamentais difusas.

O Plano de Gerenciamento de resíduos - PGR - vem descrito como integrante do processo de licenciamento ambiental de empreendimentos ou atividades pelo órgão competente do SISNAMA, exceto dos não sujeitos a licenciamento ambiental, quando a aprovação será sujeita à autoridade municipal. Nesta análise da lei, é preciso deixar claro que vários instrumentos de planejamento e gestão de resíduos descritos já existiam anteriormente, mas agora há a consolidação e a reafirmação do escopo e destinação dos mesmos, sendo mencionados em uma fonte primária - a lei $12.305 / 2010$.
A Logística Reversa passa a ser uma prerrogativa nacional, obrigando fabricantes, importadores, distribuidores e comerciantes de determinados produtos a desenvolver ações, procedimentos e meios destinados a viabilizar a coleta e a restituição dos resíduos sólidos ao setor empresarial, para reaproveitamento, em seu ciclo ou em outros ciclos produtivos, bem como diversa destinação final ambientalmente adequada. O grupo relacionado à Logística Reversa são os nós da cadeia de:

a) agrotóxicos, seus resíduos e embalagens, assim como outros produtos cuja embalagem, após o uso, constitua resíduo perigoso, observadas as regras de gerenciamento de resíduos perigosos previstas em lei ou regulamento, em normas estabelecidas pelos órgãos do SISNAMA, do SNVS e do SUASA, ou em normas técnicas;

b) pilhas e baterias;

c) pneus;

d) óleos lubrificantes, seus resíduos e embalagens;

e) lâmpadas fluorescentes, de vapor de sódio e mercúrio e de luz mista;

f) produtos eletroeletrônicos e seus componentes.

A própria definição de Logística Reversa expressa na lei amplia este escopo. Crê-se que, com o aumento das opções tecnológicas de reaproveitamento e transformação disponíveis no país, a listagem acima poderá ser ampliada no futuro.

Com a criação do banco de dados do sistema de Logística Reversa (os inventários, o sistema declaratório anual de resíduos sólidos, os Sistemas Nacionais de Informação SINIR e SINISA, os cadastros e licenciamentos) - Figura 1 -, será possível no futuro ter um banco de resíduos, facilitando a criação de parques ecoeficientes, nos quais os resíduos de uma empresa tornam-se matéria-prima de outra organização e há uma simbiose industrial.

A lei $\mathrm{n}^{\mathrm{O}} 12.305 / 2010$ foi regulamentada pelo Decreto $\mathrm{n}^{\mathrm{o}} 7.404 / 2010$, de 23 de dezembro de 2010. Como primeira ação, o decreto institui o Comitê Interministerial da Política Nacional de Resíduos Sólidos, composto por membros do Ministério do Meio Ambiente (Presidência), Ministério das Cidades, Ministério do Desenvolvimento Social e Combate à Fome, Ministério da Saúde, Ministério de Minas e Energia, Ministério da Fazenda, Ministério do Planejamento, Orçamento e Gestão, Ministério do Desenvolvimento, Indústria e Comércio Exterior, Ministério da Agricultura, Pecuária e Abastecimento, Ministério da Ciência e Tecnologia e a Secretaria de Relações Institucionais da Presidência da República. 
São competências do Comitê:

I - instituir os procedimentos para elaboração do Plano Nacional de Resíduos Sólidos, observado o disposto no art. 15 da Lei ${ }^{\circ} 12.305$, de 2010;

II - elaborar e avaliar a implementação do Plano Nacional de Resíduos Sólidos, observado o disposto no art. $15 \mathrm{da}$ Lei ${ }^{\circ} 12.305$, de 2010;

III - definir as informações complementares ao Plano de Gerenciamento de Resíduos Sólidos Perigosos, conforme 0 art. 39 da Lei $n^{\circ}$ 12.305, de 2010;

IV - promover estudos e propor medidas visando à desoneração tributária de produtos recicláveis e reutilizáveis e a simplificação dos procedimentos para o cumprimento de obrigações acessórias relativas à movimentação de produtos e embalagens fabricados com estes materiais; $\mathrm{V}$ - promover estudos visando à criação, modificação e extinção de condições para a utilização de linhas de financiamento ou creditícias de instituições financeiras federais;

VI - formular estratégia para a promoção e difusão de tecnologias limpas para a gestão e o gerenciamento de resíduos sólidos;

VII - incentivar a pesquisa e o desenvolvimento nas atividades de reciclagem, reaproveitamento e tratamento dos resíduos sólidos;

VIII - propor medidas para a implementação dos instrumentos e efetivação dos objetivos da Política Nacional de Resíduos Sólidos;

IX - definir e avaliar a implantação de mecanismos específicos voltados para promover a descontaminação de áreas órfãs, nos termos do art. 41 da Lei ${ }^{\circ} 12.305$, de 2010;

X - implantar ações destinadas a apoiar a elaboração, implementação, execução e revisão dos planos de resíduos sólidos referidos no art. 14 da Lei n $^{\circ} 12.305$, de 2010; e XI - contribuir, por meio de estudos específicos, com o estabelecimento de mecanismos de cobrança dos serviços de limpeza urbana e manejo de Resíduos Sólidos Urbanos pelos seus respectivos titulares (BRASIL, 2010b).

O texto do decreto reforça a responsabilidade coletiva na gestão de resíduos. Destaca-se a responsabilidade do gerador doméstico a observar o correto acondicionamento, bem como a coleta ou a devolução, sem constranger as regras instituídas pelo poder público em relação à questão. Os consumidores que descumprirem as respectivas obrigações previstas nos sistemas de Logística Reversa e de coleta seletiva estarão sujeitos à penalidade de advertência. Em caso de reincidência no cometimento da infração prevista, poderá ser aplicada a penalidade de multa, no valor de $\mathrm{R} \$$ 50,00 (cinquenta reais) a $\mathrm{R} \$ 500,00$ (quinhentos reais), podendo ser convertida em serviços de preservação, melhoria e recuperação da qualidade do meio ambiente.

Em relação à coleta seletiva, deverá ser implantada pelo titular do serviço público de limpeza urbana e manejo de resíduos sólidos, observando ao menos a separação de resíduos secos e úmidos. Observa-se que a implantação do sistema de coleta seletiva não deve acarretar prejuízos à implementação de sistemas de Logística Reversa. O sistema de Logística Reversa de agrotóxicos, seus resíduos e embalagens, seguirá o disposto na Lei $\mathrm{n}^{\circ} 7.802$, de 11 de julho de 1989, e no Decreto ${ }^{\circ} 4.074$, de 4 de janeiro de 2002. Os sistemas de Logística Reversa possuem uma observação importante nos artigos 16 e 17 do decreto $n^{\circ} 7.404 / 2010$ :

Art. 16. Os sistemas de Logística Reversa dos produtos e embalagens previstos no art. 33, incisos I a IV, da Lei $\mathrm{n}^{\mathrm{o}} 12.305$, de 2010 , cujas medidas de proteção ambiental podem ser ampliadas, mas não abrandadas, deverão observar as exigências específicas previstas em:

I - lei ou regulamento;

II - normas estabelecidas pelos órgãos do Sistema Nacional do Meio Ambiente - SISNAMA, do Sistema Nacional de Vigilância Sanitária - SNVS, do Sistema Único de Atenção à Sanidade Agropecuária - SUASA e em outras normas aplicáveis; ou

III - acordos setoriais e termos de compromisso.

Art. 17. Os sistemas de Logística Reversa serão estendidos, por meio da utilização dos instrumentos previstos no art. 15, a produtos comercializados em embalagens plásticas, metálicas ou de vidro, e aos demais produtos e embalagens, considerando prioritariamente o grau e a extensão do impacto à saúde pública e ao meio ambiente dos resíduos gerados.

Parágrafo único. A definição dos produtos e embalagens a que se refere o caput deverá considerar a viabilidade técnica e econômica da Logística Reversa, a ser aferida pelo Comitê Orientador. (BRASIL, 2010b).

Conforme o decreto, na gestão e no gerenciamento de resíduos sólidos deverá ser observada a seguinte ordem de prioridade: não geração, redução, reutilização, reciclagem, tratamento dos resíduos sólidos e disposição final ambientalmente adequada dos rejeitos. Valorizando o 
papel social da Logística Reversa, esta deverá priorizar a participação de cooperativas ou de outras formas de associação de catadores de materiais reutilizáveis e recicláveis constituídas por pessoas físicas de baixa renda. O texto destaca o que deve conter cada plano, bem como abrir a possibilidade de integração dos planos dos geradores em coletivo (se os geradores tiverem relação entre si).

As iniciativas previstas no art. 42 da Lei $\mathrm{n}^{\circ} 12.305$, de 2010, serão fomentadas por meio das seguintes medidas indutoras:

I - incentivos fiscais, financeiros e creditícios;

II - cessão de terrenos públicos;

III - destinação dos resíduos recicláveis descartados pelos órgãos e entidades da administração pública federal às associações e cooperativas dos catadores de materiais recicláveis, nos termos do Decreto $\mathrm{n}^{\circ} 5.940$, de 25 de outubro de 2006;

IV - subvenções econômicas;

V - fixação de critérios, metas e outros dispositivos complementares de sustentabilidade ambiental para as aquisições e contratações públicas;

VI - pagamento por serviços ambientais, nos termos definidos na legislação; e

VII - apoio à elaboração de projetos no âmbito do Mecanismo de Desenvolvimento Limpo - MDL ou quaisquer outros mecanismos decorrentes da Convenção Quadro de Mudança do Clima das Nações Unidas. (BRASIL, 2010).

Por fim, modifica-se o Decreto ${ }^{\circ}$ 6.514, de 2008, que passa a vigorar acrescido do seguinte artigo:

Art. 71-A. Importar resíduos sólidos perigosos e rejeitos, bem como os resíduos sólidos cujas características causem dano ao meio ambiente, à saúde pública e animal e à sanidade vegetal, ainda que para tratamento, reforma, reuso, reutilização ou recuperação:

Multa de R \$ 500,00 (quinhentos reais) a R $\$ 10.000 .000,00$ (dez milhões de reais). (NR) (BRASIL, 2008).

A Figura 1, ao estabelecer as responsabilidades da sociedade, empresas e governo, permite estabelecer amplos questionamentos sobre como cada um destes entes deve assumir responsabilidades sobre a cadeia de resíduos. Como parte destes questionamentos, é apresentada a Figura 2, focando os Resíduos de Serviços de Saúde (LUIZ-PEREIRA, 2011). Durante sua discussão, a aplicação do modelo para os hospitais Pro-hosp contextualiza os entes abordados na Figura 1: empresas (os hospitais), o governo (Secretaria de Estado de Saúde de Minas Gerais) e a sociedade mineira.

\subsection{A Cadeia Logística Reversa de Resíduos de Serviços de Saúde dos Hospitais Públicos de Minas Gerais}

A Figura 2 apresenta a cadeia Logística Reversa de Resíduos de Serviços de Saúde dos hospitais públicos Pro-hosp, aplicando os conceitos da PNRSU.

1. Não há evidências de que exista uma preocupação com a redução da geração, que é um dos pilares do gerenciamento reverso eficiente. Em se tratando de saúde, os questionários relatam uma atenção com a biossegurança que não se desdobra em uma preocupação com o impacto ambiental. Isso é especialmente preocupante, pois o volume de RSS em 2009 de todas as Organizações Prestações de Serviços de Saúde - OPSS - do Brasil correspondeu a $3,88 \%$ do total de RSU, sendo que na região sudeste a proporção é de 5,06\%, conforme dados da ABRELPE (2010).

2. A segregação é deficiente: os profissionais não têm segurança em classificar os resíduos corretamente. Esse dado é corroborado pelos contatos frequentes do hospital com o e-mail de suporte da pesquisa para tirar dúvidas sobre RSS. A comparação das taxas de geração dos hospitais Pro-hosp apresentou-se maior que os parâmetros brasileiros e internacionais, não sendo possível afirmar com segurança se o volume é realmente grande de resíduos contaminantes ou se descartes inócuos foram indevidamente classificados como de risco.

2.1 A parcela de 8,6\% da amostra de hospitais Pro-hosp afirmou que não há segregação de resíduos nos subgrupos A1, A2, A3, A4 e A5. Já 2,1\% afirmaram que os resíduos do grupo E são misturados aos do grupo A. Conforme relato no questionário, a vigilância sanitária estadual de Minas Gerais não solicita a classificação dos resíduos do grupo A nos subgrupos. Ferreira Jr. (2001) ressalta que a classificação dos resíduos é complexa, com várias variáveis, como periculosidade e insalubridade. Além disso, quanto maior a complexidade do manejo, maior o custo.

2.2 A segregação de resíduos do grupo B ocorre segundo os preceitos legais nos hospitais.

2.3 A segregação de resíduos do grupo $\mathrm{C}$ é eficiente, pois há estrito acompanhamento do CNEN. 


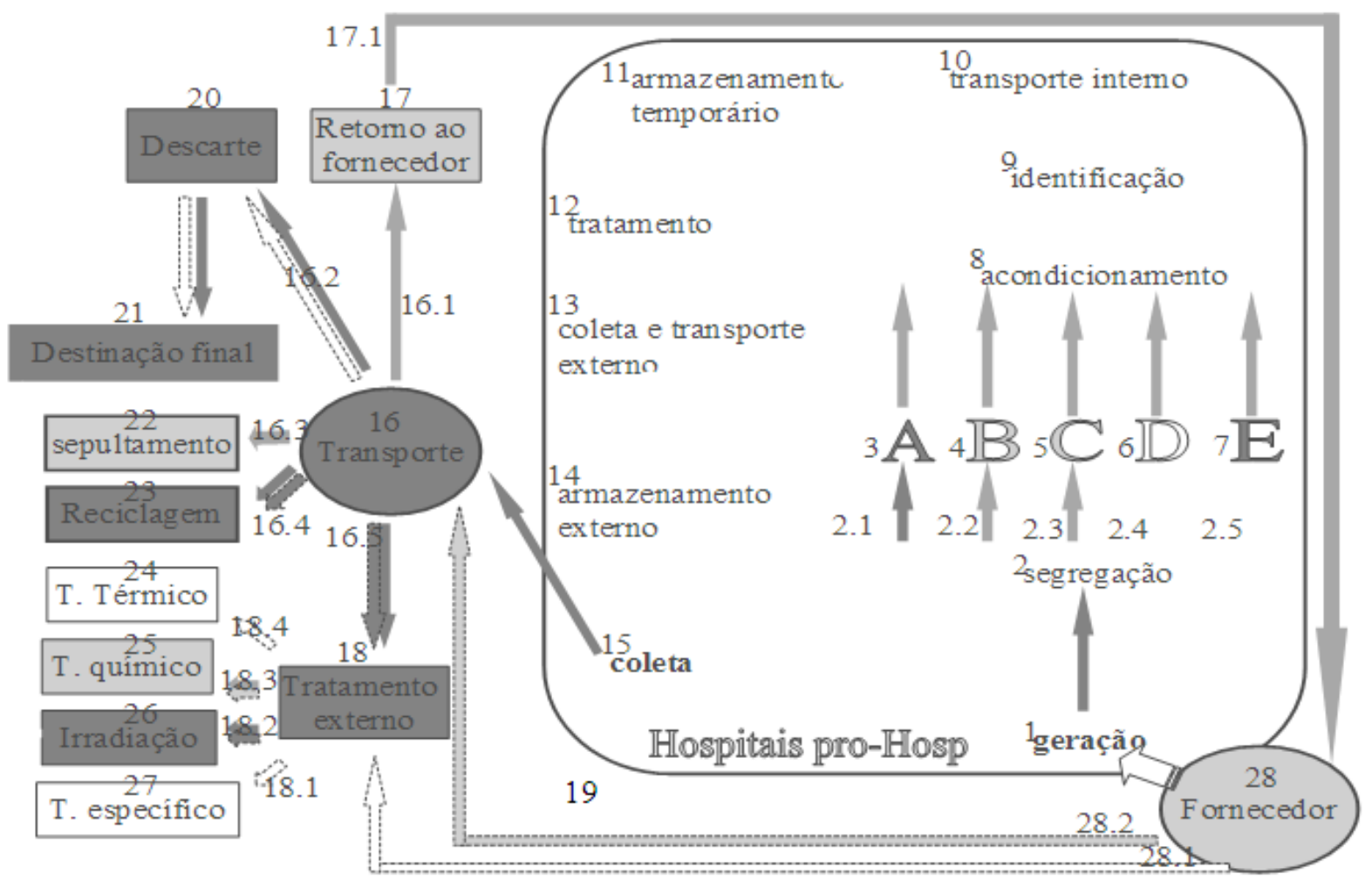

FIGURA 2 - CADEIA LOGÍSTICA REVERSA DOS RESÍDUOS DE SERVIÇOS DE SAÚDE DOS HOSPITAIS PRO-HOSP 2010. FONTE: Luiz-Pereira (2011).

2.4 Os resíduos comuns são segregados de maneira adequada, mas carecem de ser subdivididos em recicláveis e não recicláveis em todos os hospitais. Assim, seria possível reaproveitar $90,52 \%$ dos resíduos comuns gerados.

2.5 A segregação de perfurocortantes (grupo E) carece de melhor observância visando à segregação adequada desse grupo. O uso de caixas específicas (como as da marca Descapark $\left.{ }^{\circledR}\right)$ aumenta a eficiência do processo de segregação, mas como ocorre pelo menos um acidente com esse resíduo com funcionários da limpeza, é um forte indicador de que há erros no processo. Nesses casos, os perfurocortantes podem estar indo junto à roupa de cama $\mathrm{e}$ não no recipiente de descarte, por exemplo.

3. Os resíduos do grupo A, ao não serem segregados, provocam um aumento do custo de tratamento de resíduos, pois descartes que não precisam ser tratados acabam recebendo tratamento especial, que é mais caro. Aproximadamente $69,06 \%$ dos resíduos do grupo A não requerem tratamento, conforme questionário. Apesar disso, 100\% desses resíduos são encaminhados a tratamento.

4. Não há evidências de que a segregação de resíduos do grupo B seja inadequada.

5. A segregação de resíduos do grupo $\mathrm{C}$ é adequada, pelo mesmo motivo do item 2.3.

6. Os resíduos comuns são segregados de forma adequada, mas não prezam pela redução, reciclagem nem reuso. O percentual de 90,72 dos resíduos desse grupo possui potencial de ser reciclado.

7. O principal problema da segregação do grupo E é a mistura com resíduos do grupo A, causando contaminação.

8. $\mathrm{O}$ acondicionamento apresenta-se como adequado em mais de $90 \%$ dos hospitais.

9. A identificação correta dos grupos segregados não é totalmente adequada, em decorrência do que foi mencionado sobre os grupos A e E. 
10. O transporte interno conta com carrinhos adequados, mas há hospitais que usam o mesmo carrinho para resíduos comuns e RSS.

11. Dos hospitais Pro-hosp, $52,17 \%$ informaram possuir um abrigo temporário interno para RSS, ainda que fosse preciso que todos tivessem. Pelo questionário, os hospitais Pro-hosp informaram que $97,83 \%$ dos RSS são acondicionados em sacos e/ou recipientes impermeáveis, resistentes a punctura, ruptura e vazamentos quando destinados ao abrigo temporário. Os hospitais Pro-hosp informaram que $95,65 \%$ possuíam abrigo externo e $4,35 \%$ não possuíam.

12. Pelo questionário, os hospitais Pro-hosp realizam os seguintes tratamentos de resíduos: autoclavagem fora do município: 1,56\%; incineração fora do município: 37,5\%; autoclavagem no mesmo município: 7,8\%; pirólise no mesmo município: $3,1 \%$; autoclavagem dentro do hospital: 15,6\%; envio direto para aterro sanitário: $3,1 \%$; nenhum tratamento: $3,1 \%$; processo químico: $3,1 \%$; pirólise fora do município: $3,1 \%$; autoclavagem fora do município: $10,9 \%$; incineração na área física do hospital: 6,25\%; queima em forno comum: 1,56\%; incineração no mesmo município: 3,1\%.

13. A coleta e o transporte interno, segundo Luiz-Pereira e Coelho (2009), apresentam problemas nesses hospitais, como as rotas dos resíduos que cruzam a de roupa limpa e material esterilizado.

14. Há hospitais que não contam com armazenamento externo adequado, expondo a comunidade hospitalar aos riscos, quando próximos à área correspondente. Além disso, há o risco de que animais transmissores de doenças tenham acesso a esse acondicionamento.

15 e 16. A coleta e o transporte, conforme relatado nos questionários, nem sempre ocorrem corretamente, pois a chegada do caminhão de coleta nem sempre bate com o horário esperado de recolhimento determinado pelo fluxo interno do hospital. Falta um registro geral em Minas Gerais, a exemplo do CADRI em São Paulo e do ATRP na Bahia, para ser requerido pelos hospitais. A FEAM apenas autoriza o serviço, mas não sabe informar quem são as empresas ambientalmente adequadas. Em 2009, no Brasil, $88,15 \%$ dos RSU foram coletados (não há porcentagem de RSS coletado no período). Como as Vigilâncias Sanitárias vinculam a coleta ao alvará de funcionamento, quando não há a oferta pública de coleta, as OPSS terceirizam a empresas particulares.

16.1 As respostas nos questionários sugerem que o transporte de resíduos ao fornecedor tem ocorrido conforme esperado.
16.2 Os transportes de resíduos dos fornecedores, por serem em volume pequeno, são feitos adequadamente. Já o transporte de resíduos dos hospitais carece de melhor supervisão, pois não foi possível levantar a informação de como esse processo acontece, em órgãos oficiais.

16.3 O transporte para sepultamento ocorre conforme esperado, pois, via de regra, as partes e o todo de corpos sem vida não requerem condições extraordinárias de transporte. Em muitos casos, usa-se o carro funerário ou ambulância.

16.4 Apenas 25,53\% dos hospitais contavam com serviço de coleta seletiva de resíduos do grupo $\mathrm{D}$ e que participavam dessa iniciativa; 4,25\% não separavam, mesmo havendo uma coleta seletiva.

16.5 A maior capacidade de tratamento de RSS em Minas Gerais ocorre através do método de incineração/pirólise (22 t./dia). Autoclavagem pode tratar 10 t./dia. Não há o serviço de ETD disponível em Minas Gerais (ABRELPE, 2007).

17 e $17.1 \mathrm{O}$ retorno ao fornecedor ocorre, segundo descrito nos questionários, em casos de devolução de insumos, transcorrendo de forma aceitável pelos hospitais. Não se evidenciou nesta pesquisa RSS encaminhado de volta ao fornecedor de insumos.

18. O tratamento externo tem acontecido de forma inadequada. Conforme explicitado anteriormente, procedimentos que poderiam ser realizados de maneira mais segura e mais barata no interior do OPSS são realizados fora. Os altos custos de instalação dos equipamentos podem ser a razão. Em 2009, 32\% dos RSS do Brasil foram tratados. $\mathrm{Na}$ região sudeste, $45 \%$ passam por tratamento. Cabe questionar se a gestão desse tratamento segue o modelo de Betim (que inclui tudo como perigoso e custa $2.042,73 \%$ mais caro que com o RSU) ou de Belo Horizonte (que faz a gestão pública de RSS e a segregação adequada de RSS e que custa $1,88 \%$ mais caro que com os RSU).

18.1 e 27. Tratar RSS em Minas Gerais é um procedimento caro. $\mathrm{O}$ equipamento de autoclavagem custa de 2 mil a 12 mil reais. A autoclavagem com fusão (seringas com agulhas) requer aparelhos que custam 24 mil reais em média. $\mathrm{O}$ equipamento de autoclave com vapor e micro-ondas custa 600 mil reais em média. Esses valores podem ser um indicativo da razão pela qual determinados tratamentos de resíduos são feitos fora dos hospitais, de modo a evitar os custos de aquisição.

18.2 e 26. O tratamento por irradiação não está disponível em Minas Gerais, obrigando os geradores de resíduos que queiram utilizar essa forma de tratamento a enviar os RSS para outros Estados. 
18.3 e 25. As formas de tratamento químico, segundo a coleta via questionário, apresentam-se de maneira adequada na maioria dos casos. Recomenda-se verificar a forma de neutralização de componentes utilizados para desinfecção em estudo complementar.

18.4 e 24. O tratamento térmico, apesar dos riscos ambientais e à saúde das pessoas, é requerido para o tratamento de determinados resíduos, em especial o envio para incineração.

19. Os questionários permitem afirmar que nenhum hospital da amostra evidencia a preocupação com o ambiente externo - delegam a serviços públicos ou terceirizados seus RSS, sem procurar saber a fundo o destino e as condições de destinação final.

20. Os dados primários e secundários desta pesquisa indicam que o descarte não se tem pautado pela segurança ambiental e proteção à saúde. É preciso destacar que o perigo de contaminação por RSS após o descarte é um assunto polêmico. Rutala e Mayhall (1992) destacam vários estudos que afirmam que, uma vez descartados, os RSS não apresentam maior risco biológico que os domiciliares em igual condição. Apesar disso, a presente pesquisa destaca o risco de contaminação antes do descarte, com perigo considerável e não contestado por pesquisadores em microbiologia. Os demais riscos, como perfuração, complicações decorrentes de ferimentos com cortes e perfurações, intoxicação com compostos químicos, danos ao meio ambiente, irradiação existem antes e após o descarte inadequado.

21. O lixão, a pior forma de disposição de resíduos, ainda está presente em 7,48\% dos municípios com hospitais Pro-hosp. O aterro controlado foi o destino prevalente para os RSS dos hospitais Pro-hosp, com 40,19\%. A porcentagem de aterros sanitários/usina de triagem e compostagem devidamente regulamentados foi da ordem de 24,30.

22. O sepultamento de partes amputadas é oferecido de forma direta e fácil aos hospitais, nos cemitérios.

23. 97,82\% dos hospitais declararam separar os RSS segundo suas características físicas, químicas e biológicas, sua espécie e estado físico. Separar apenas não é suficiente, mas sim encaminhar para a reciclagem, quando disponível. $2,18 \%$ declararam não dividir. Pelo menos R \$2.222.357,69 não são aproveitados todos os anos, apenas com os resíduos comuns, nos hospitais Pro-hosp.

28. As práticas do fornecedor, conforme Luiz-Pereira e Coelho (2009), acabam passando despercebidas, pois o foco do monitoramento de resíduos têm sido as organizações prestadoras de serviços de saúde. As evidências atuais indicam que essa questão é gerenciada conforme a legislação em vigor, na maioria dos casos.

28.1 Não há dados sobre o envio de RSS gerados pelos fornecedores, mas o atendimento às condições de transporte sugere que isso ocorra de maneira adequada.

28.2 O transporte de insumos pelo fornecedor tem ocorrido conforme a legislação vigente (LUIZ-PEREIRA; COELHO, 2009).

Ao identificar a cadeia logística reversa dos resíduos de serviços de saúde dos hospitais Pro-Hosp, foi possível delinear um fluxo da cadeia reversa de resíduos, inserindo fornecedores, geradores, transportadores e operadores das destinações finais em um mesmo contexto. Destaca-se que a Figura 2 representa uma forma metodológica clara de nortear esta análise.

A região sudeste do Brasil apresenta uma média de RSS em relação aos RSU maior que a média nacional. Isso demonstra que há uma necessidade de adoção de medidas que reduzam a produção na fonte, de modo a evitar o desperdício, diminuir o volume gerado e reduzir os gastos decorrentes do gerenciamento reverso. Para que a gestão de resíduos seja realizada de forma adequada, é preciso que as pessoas sejam devidamente capacitadas para que saibam identificar, segregar, acondicionar, transportar e dar o correto destino para cada grupo de resíduos de serviços de saúde. Deficiências de treinamento podem resultar em acidentes com perfurocortantes em profissionais de limpeza, contaminação por agentes patógenos em profissionais de assistência à saúde, danos ao meio ambiente e exposição da população aos riscos.

O gerenciamento reverso incorreto resulta também na segregação de RSS de forma errada, na qual tudo é considerado contaminado. Assim, são investidos maiores recursos no tratamento da massa total de RSS maior que o necessário. Este recurso poderia ser usado na aquisição de novos equipamentos, manutenção dos existentes, construção de estruturas para novos serviços ou mesmo na capacitação das pessoas.

Como apresentado nos resultados, 90,72\% dos resíduos comuns possuem potencial de reciclagem. A falta de atenção com este potencial perdido joga no lixo um montante financeiro significativo (mais de R\$ 2 milhões de reais), além de aumentar o volume de material descartado, requerendo maiores investimentos do poder público na construção de aterros. A destinação final foi outro problema relevante, pois nem todos os municípios com hospitais Pro-Hosp contavam com aterros sanitários 
e Usina de triagem/compostagem regularizados. Além dos riscos ao meio ambiente e à população, o depósito de RSS em locais inadequados não reintegra os resíduos a uma cadeia de suprimentos.

Como sugestão de melhoria do gerenciamento reverso de resíduos por parte do Estado, recomenda-se a instituição de um licenciamento oficial das empresas transportadoras de RSS. Assim, os hospitais Pro-hosp poderiam requerer o número de licenciamento no momento da aquisição do serviço. Para este licenciamento, deveriam ser observados critérios de estrutura, processos e resultados em uma abordagem de segurança dos envolvidos, do meio ambiente e da saúde coletiva.

\section{Considerações finais}

O Estado assume papel importante no incentivo à formação dos rearranjos que integrem a gestão de resíduos anteriormente mencionados. Entre os instrumentos, destacam-se os incentivos fiscais, financeiros e creditícios, no campo tributário; na pesquisa científica e tecnológica; no fomento às cooperativas de reciclagem e demais formas de reaproveitamento; na vigilância sanitária, ambiental e agropecuária; nos recursos do Fundo Nacional do Meio

\section{Referências}

ABRELPE. Panorama dos resíduos sólidos do Brasil 2009. São Paulo: ABRELPE, 2007.

. Panorama dos resíduos sólidos do Brasil 2008. São Paulo: ABRELPE. 2010.

ABRUCIO, Fernando Luiz. Trajetória recente da gestão pública brasileira: um balanço crítico e a renovação da agenda de reformas. Rev. Adm. Pública, Rio de Janeiro, v. 41, n. esp., p. 67-86, 2007.

AGUIAR, Afrânio Carvalho. Atividades cooperativas de pesquisa científica e tecnológica em Minas Gerais: projetos, redes e consórcios. CEPEAD-UFMG. Disponível em: $<$ http:// www.cordoba.cepead.face.ufmg.br/banco_teses/teses/89/ d16022004aca.pdf>. Acesso em: 30/09/2009.

BOWERSOX, D. J.; CLOSS, D. J. Logística empresarial: o processo de integração da cadeia de suprimentos. Tradução da equipe do Centro de Estudos em Logística. São Paulo: Atlas; 2001.
Ambiente e do Desenvolvimento Científico e Tecnológico; na importância da educação continuada e capacitações; na disponibilização de linhas de financiamento para infraestrutura, projetos, coleta seletiva, Logística Reversa, descontaminação de áreas contaminadas e outros. Reafirma, assim, o papel do Estado de atuar subsidiariamente na minimização da cessão do dano decorrente de resíduos, sem isentar os responsáveis pelo dano de ressarcir integralmente o poder público pelos gastos decorrentes das ações empreendidas.

A lei sabiamente atentou para o fato de que, tão importante quanto se pensar no que se fazer com o resíduo, é preciso pensar na prevenção da geração e na segurança ambiental e das pessoas. Aplicando os conceitos da nova PNRSU aos hospitais Pro-hosp, percebe-se que há um longo caminho a percorrer. Na adequação à nova legislação vigente, apenas a promulgação da lei não é suficiente para garantir que a gestão de resíduos seja eficiente, mas é um primeiro e importante passo no alcance da responsabilidade da sociedade brasileira com o espaço urbano/meio ambiente.

A nova Política Nacional de Resíduos Sólidos Urbanos foi delineada na Figura 1, sistematizada na área de Resíduos de Serviços de Saúde representada pela Figura 2. Os resultados foram descritos conforme a metodologia proposta, alcançando os objetivos específicos e o geral propostos.
BRASIL. Lei $n^{\circ}$ 6.938, de 31 de agosto de 1981. Dispõe sobre a Política Nacional do Meio Ambiente, seus fins e mecanismos de formulação e aplicação, e dá outras providências. Brasília, 31 de agosto de 1981.

\section{Constituição da República Federativa do Brasil.} Brasília, 5 de outubro de 1988.

. Decreto $n^{\circ} 6.514$, de 22 de julho de 2008. Dispõe sobre as infrações e sanções administrativas ao meio ambiente, estabelece o processo administrativo federal para apuração destas infrações, e dá outras providências. Brasília, 22 de julho de 2008.

. Lei $n^{\circ} 12.305$, de 23 de dezembro de 2010. Institui a Política Nacional de Resíduos Sólidos. Brasília, 2 de agosto de 2010a.

Decreto $n^{\circ} 7.404$, de 23 de dezembro de 2010. Institui a Política Nacional de Resíduos Sólidos. Brasília, 23 de dezembro de 2010 b. 
CIPLET, David. An industry blowing smoke (10 reasons why gasification, pyrolysis \& plasma incineration are not "green solutions"). GAIA, Berkeley, jun. 2006.

CMMAD - Comissão Mundial Sobre o Meio Ambiente e Desenvolvimento. Nosso futuro comum. Rio de Janeiro: Fundação Getúlio Vargas, 1988. 430 p.

COUNCIL OF SUPPLY CHAIN MANAGEMENT PROFESSIONALS (CSCMP). Supply chain and logistics terms and glossary. 2010. Disponível em: <http://www.cscmp.org/digital/ glossary/document.pdf $>$. Acesso em: 14/01/2010.

CUNHA, Valeriana; CAIXETA FILHO, José Vicente. Gerenciamento da coleta de Resíduos Sólidos Urbanos: estruturação e aplicação de modelo não linear de programação por metas. Gestão \& Produção, v. 9, n. 2, p. 143-161, ago. 2002.

DORNIER, Philippe-Pierre; ERNEST, Richard; FENDER, Michel; KOUVELIS, Panos. Logística e operações globais: texto e casos. São Paulo: Atlas, 2000.

FERREIRA JR., Anjos L. Aspectos de saúde coletiva e ocupacional associados à gestão dos resíduos sólidos municipais. Cad. Saúde Pública, Rio de Janeiro, n. 17, p. 689-696, 2001.

GARCIA, Leila Posenato; ZANETTI-RAMOS, Betina Giehl. Gerenciamento dos Resíduos de Serviços de Saúde: uma questão de biossegurança. Cad. Saúde Pública, Rio de Janeiro, v. 20, n. 3, p. 23-40, junho 2004.

GIL, Antonio Carlos. Como elaborar projetos de pesquisa. 4. ed. São Paulo: Atlas, 2002.

GOTO, A. K.; SOUZA, M. T. S. A contribuição da Logística Reversa na Gestão de Resíduos Sólidos: uma análise dos Canais Reversos de Pneumáticos. In: ENCONTRO DA ASSOCIAÇÃO NACIONAL DE PÓS-GRADUAÇÃO E PESQUISA EM ADMINISTRAÇÃO, Rio de Janeiro, 2008. ENCONTRO DA ASSOCIAÇÃO NACIONAL DE PÓS-GRADUAÇÃO E PESQUISA EM ADMINISTRAÇÃO, 32., Rio de Janeiro, 2008. Anais... Rio de Janeiro, 2008. p. 1-16.

IBGE - Instituto Brasileiro de Geografia e Estatística. Pesquisa Nacional de Saneamento Básico - 2008. Brasília: IBGE. 2008.

KAST, Fremont E.; ROSENWEIG, James E. Organização e administração: um enfoque sistêmico. São Paulo: McGraw-Hill, 1970.

LAMBERT, Douglas M.; STOCK, James R.; VANTINE, J. G. Administração estratégica da Logística. São Paulo: Vantine Consultoria, 1999.

LUIZ-PEREIRA, André. Logística Reversa de Resíduos de Serviços de Saúde de Minas Gerais. 196 f. Dissertação (Mes- trado em Administração) - Universidade Fumec/FACE, Belo Horizonte, 2011.

; COELHO, Elaine Gonçalves. $1^{\circ}$ diagnóstico de Resíduos de Serviços de Saúde de Minas Gerais. Belo Horizonte: SES-MG, dez. 2009.

MACHADO, Maria de Fátima Antero Sousa et al. Integralidade, formação de saúde, educação em saúde e as propostas do SUS: uma revisão conceitual. Ciênc. Saúde Coletiva, Rio de Janeiro, v. 12, n. 2, p. 335-342, abr. 2007.

MARCONI, Marina de Andrade; LAKATOS, Eva Maria. Metodologia do trabalho científico. São Paulo: Atlas, 1995.

MINAS GERAIS. Secretaria de Estado de Saúde. Assessoria de Gestão Estratégica. Acordo de resultados. Belo Horizonte: Gerência de Acompanhamento e Avaliação, 2006a.

Secretaria de Estado de Saúde. Manual do programa de fortalecimento e melhoria da qualidade dos hospitais do SUS/MG (Pro-Hosp). Belo Horizonte: SES-MG, $2006 \mathrm{~b}$.

MUCELIN, Carlos Alberto; BELLINI, Marta. Lixo e impactos ambientais perceptiveis no ecossistema urbano. Uberlândia: Sociedade \& Natureza, 2008.

RICHARDSON, Helen. Logistics in reverse. Cleveland: Industry Week, 2001.

ROGERS, D. S.; TIBBEN-LEMBKE, R. S. Going Backwards: Reverse Logistics Trends and Practice. Reverse Logistics Executive Council, 1999. Disponível em: <http://www.rlec. org/reverse.pdf > . Acesso em: 30/10/2009.

ROMEIRO, Ademar Ribeiro. Meio ambiente e dinâmica de inovações na agricultura. São Paulo: Annablume/FAPESP, 1998.

RUTALA, W. A.; MAYHALL, C. G. Medical waste: infection control and hospital epidemiology. Hospital Epidemiology and Infection Control, v. 13, n. 1, p. 794-797, 1992.

SACHS, Ignacy. Desarrollo sustentable, bio-industrialización descentralizada y nuevas configuraciones rural-urbanas. Los casos de India y Brasil. S.n. Pensamiento Iberoamericano, v. 46, p. 235-256, 1990.

SILVA, Carlos Ernando da; HOPPE, Alessandro Eduardo. Diagnóstico dos Resíduos de Serviços de Saúde no interior do Rio Grande do Sul. Eng. Sanit. Ambient., Rio de Janeiro, v. 10, n. 2, p. 146-151, jun. 2005. Disponível em: <http://www.scielo.br/scielo.php?script=sci_arttext\&pid=S1413-41522005000200008\&ln $\mathrm{g}=\mathrm{en \& nrm}=$ iso $>$. Acesso em: 01/02/2010.

Recebido em março de 2011. Aceito em maio de 2011. Publicado em dezembro de 2011. 